\title{
Paid and Unpaid Labor on the Frontline State
}

My first opportunity to observe a local manager's work routines involved waking up at two oclock in the morning. Local manager Paulino had asked me to meet him at a petrol station on the edge of Cajamarca city, from which a combi would depart in the darkness at three o'clock for Labaconas District. The shuddering old minibus was packed with dozing travelers, many of whom would disembark at one or another of the tiny villages tucked between the hairpin turns of the only road connecting Cajamarca to Labaconas. Over the course of two hours, as the combi snaked its way through the mountains, Paulino told me how he came to work for Juntos, what the work entailed, and what it meant to him personally. Efforts to evaluate social programs often focus on these programs' intended beneficiaries. Yet when we gloss over the people who implement social programs, or fail to take their experiences seriously, we miss an opportunity to identify unintended consequences and broader social impacts.

In previous chapters, I discussed how local managers relied on Juntos recipients to walk and wait and manage up in order to implement and monitor conditions. Did local managers in Cajamarca rely on mothers to help them do their jobs because they were lazy or felt entitled to make such requests? Or was this a larger institutional issue related to program design, in which case we could understand walking and waiting and managing up as instances of the state's reliance on women's unpaid labor? Conversations like the one I had with Paulino in the combi, and with other local managers over meals and in the clinics, schools, and Internet cafes where they did their work, helped me to answer these questions. In the following pages, I offer an unflinching account of just how difficult it is to be a Juntos local manager in a rural mountainous region. In addition to humanizing 
a cohort of workers who might otherwise be perceived as "bad actors," I hope to make a broader point about what we should expect to happen when policy makers require local workers to monitor and enforce conditions under impossibly difficult circumstances.

On an unusually bright day in the Andean rainy season, one of the local managers in Labaconas District invited me to attend a meeting in Tinca village. At the meeting, Juntos recipients were to elect a new committee of Mother Leaders, and the local manager was to guide this process. The local manager had often explained to me that "the Mother Leader is the local manager in her community." I was curious about these women, especially because I could not find very much information about them on the Juntos website or in the available research on CCT programs. The little information that I could locate described Mother Leaders differently than the local manager had. Generally Mother Leaders were introduced as an informal subset of "exemplary" CCT recipients who served as elected representatives of Juntos-affiliated households (Juntos 2011). In policy documents produced by the World Bank and the United Nations Development Programme, Mother Leaders were described as a resource for achieving program aims (Grosh et al. 2008; UNDP 2006). ${ }^{1}$ I would eventually discover that Mother Leaders could be accurately described in all of these ways. By listening to local managers talk about their work, and by observing it in action, I was able to document these and several additional ways that the state relied on women's unpaid labor.

The meeting in question was held in a sky-blue village hall perched atop steep green fields already well fed by the recently begun rainy season. The village was located well above the district capital, and the local manager and I traveled there partway on a dirt bike, lent to the local manager by the mayor, and partway on foot, when the narrow footpath leading to the village became otherwise impassable. The village hall was dark and cool, a single room with a packed-earth floor. At the far end was a smokeless stove (cocina mejorada), which had been installed by a joint government and NGO initiative intent on improving women's health. The stove sat unused, however, and the women explained that "it doesn't work." A worker from that initiative later told me that many smokeless stoves sat unused because they had not been designed to accommodate the pots that women used for cooking-the stoves were too small.

The hall was furnished with a long table, a handful of wooden benches, and a small window through which the only light poured in. Women wearing muddy rubber boots arrived at the hall from the surrounding hills while, at the same time, drawing raw wool into a single strand of yarn and winding it on tall wooden palitos (sticks) - which they continued to do throughout the meeting. Twenty Juntos recipients attended the meeting, some of whom brought very young children; a few male partners sat along a bench near the back. Throughout the meeting five of the women bustled around a smoky stove (positioned beside the rejected, 
smokeless version), preparing a lunch of savory lentils and cabbage, which we all shared afterward. The following vignette is from my field notes, which begin by describing the selection of the new Mother Leaders committee.

The local manager stands at the front of the room to present the six women currently serving as Mother Leaders. He asks the six women if indeed they want to elect new leaders; three are in strong agreement, the other three appear to be less so, but in the end they decide to go ahead with the election. All of the mothers in the room are talking among themselves, and the men in the corner raise their voices requesting the women to listen up, por favor! The seated men also reproach the women who are entering and exiting the hall preparing the lunch, telling them they will have time to cook later and that they should show some manners, which "they obviously don't have." The women disregard the men's comments and continue cooking. A number of mothers suggest potential nominees, at which point the local manager urges those nominated to come forward. They do, albeit most of them rather timidly.

Gesturing to the nominees one by one, the local manager asks for a show of hands to determine who will occupy each of the six positions. One nominee, a woman named Lourdes, who is older than the rest, tells the local manager that she has been ill and is tired, and worries she wouldn't be able to do the walking required; apologizing, she says she'd prefer not to be considered. A younger woman, named Rosa, is nominated for treasurer, but the local manager elicits from her the information that she is illiterate and suggests the women elect someone else. They do so, and Rosa is given a position that doesn't require literacy. She will be a "vocal," a committee member who travels from house to house communicating information verbally. The friendly woman seated to my left is Maria. She tells me that she is twenty-nine years of age and a mother to three children. After watching me scribble notes in my field book, Maria volunteers that she is illiterate "and doesn't know anything" (no sé nada), with the kind of giggle I came to learn accompanied statements that were funny and not funny, alike. When the election is over, the new Mother Leaders return to their seats.

The local manager then raises the issue of health and education conditions (coresponsibilities), and speaks for fifteen or twenty minutes about how important it is that mothers meet these. If they do not, they will not receive their two hundred soles. He talks first about education and how their children need to study to "keep progressing." Afterward he transitions to nutrition, bringing up the municipality's guinea pig project for Juntos mothers. He makes a joke that the women must give the child the guinea pig's leg and the father the head, not the other way around, which elicits laughter. He then brings up the forthcoming reproductive-health training at the municipality in Labaconas. He says that it is important for the Mother Leaders to attend, because there are a lot of pregnant women who "continue having more and more babies."

The local manager tells the mothers not to let other people call them lazy or tell them that they don't work for their Juntos payment (soles). A number of women chime in, confirming that they've weathered these accusations, and that it isn't true, they aren't lazy. Finally, the local manager speaks about the responsibilities specific 
to Mother Leaders. They are expected to be "very self-sacrificing" despite their work not being remunerated. The Mother Leaders speak up in agreement with this; several women comment that they must travel very far to get to the meetings that local managers frequently call.

The meeting provided a view into the relationship between local managers and the select group of CCT recipients called Mother Leaders. It also indicated the importance of this relationship to Juntos's capacity to operate in the isolated and unevenly developed places that it did. In fact, the large body of research on CCT programs reveals very little about the people who carry out local-level program implementation or how they carry it out. As a result, we have an incomplete understanding of how unintended impacts are produced.

This chapter zooms in on two sets of actors formally and informally tasked with local-level program implementation-local managers and Mother Leaders. In this this book I have already introduced local managers and illustrated some of what their work entailed. In this chapter I delve deeper into what they were expected to do and what they did. Mother Leaders receive limited attention in policy-oriented literature; and where they are discussed, they are not the focus of the study (IEP 2009; Vargas Valente 2010; Molyneux and Thomson 2011). To my knowledge, no comprehensive academic analysis of Mother Leaders exists.

In the villages of Cajamarca, Mother Leaders were far more visible than they were in the literature on CCTs, and the role they played was significant. Given this, the sporadic and passing references to Mother Leaders' in the literature is surprising. Why do we know so little about them? Mother Leaders' work is not formally recognized in policy; analysis at that scale could quite easily miss them. Similarly, surveys or structured-interview research that approached program recipients as a homogenous group could easily overlook Mother Leaders. In contrast, evidence presented here illustrates the work practices and processes required to implement Juntos and, in doing so, uncovers additional layers of gendered labor and social costs.

Before I turn to the relationship between local managers and Mother Leaders, it is necessary to establish the existence of the gap that Mother Leaders helped local managers fill. This requires a look at what Lima expected local managers to do and the conditions under which they were expected to do it.

\section{LOCAL MANAGERS}

The Juntos experts we met in chapter 2 relied on a range of local managers to implement the program in its rural areas of intervention. Frontline state workers, whether bureaucrats in urban welfare offices or project implementers in rural villages, mediate the relationship between the state and its citizens (Lipsky 1980; Mosse 2005; Goetz 2001; Hossain 2010). This role imbues them with significant 
power at a local level. Frontline state workers are authorized to make decisions that affect the lives of the people they are intended to serve, and sometimes their unauthorized decisions make just as great an impact. This includes assessments of poor people's eligibility for government benefits and sanctions, as well as state workers' choices influencing the treatment poor people receive as they participate in state-sponsored programs (Lipsky 1980). The decisions that these workers make are influenced by their own biographies: their gender, ethnicity, and social class. These and other identities shape how they relate to the beneficiaries of the programs they implement and, in turn, how beneficiaries experience the state (Watkins-Hayes 2009; Hossain 2010; Radcliffe and Webb 2015).

In the case of Juntos, frontline state workers and the mothers and children they managed belonged to distinct social classes. Local managers often were technicalschool- or university-educated, lived in urban district or regional capitals, and wore Western dress. Before finding employment with Juntos, many worked as teachers, nurses, or professionals in other social programs. Local managers belong to Peru's "new middle class." Many of them came from poor families and were the first to receive secondary or postsecondary education. They spoke proudly of the sacrifices their parents had made to see their children "progress" in life (seguir adelante). It was evident from my observations and in conversations with the local managers that their personal histories and professional identities shaped the way that they carried out their work and interacted with the mothers they managed.

Hundreds of miles and mountains away from Juntos's head offices, local managers encouraged women to meet program conditions, work that they often referred to as making sure mothers "changed their behavior." They visited clinics and schools to verify that mothers had met the required conditions, and they managed data related to affiliations and suspensions by "entering the system" (entrar el sistema) on computers at the Juntos head office and in Internet cafés. Local managers advised women when payday would take place, and then they supervised the occasion. They coordinated with health and education staff and other social services to ensure that babies had birth certificates, that children were enrolled in school, and that health staff knew when the local managers would be monitoring women's compliance with conditions.

While these tasks may seem fairly straightforward, the unevenly developed landscapes over which Juntos was implemented made the work time-consuming and complex. Local managers' implementation work was geographically spread out over Cajamarca city and the countryside. Cajamarca is a city of 218,000 inhabitants, and because of its close proximity to the world's second-largest gold mine, the city had a number of "developed" comforts, such as public and private hospitals, an international school, taxis, a modern shopping mall, and Internet cafes. Yet outside the district and regional capital cities, the countryside lacked modern infrastructure and was largely isolated from urban resources. Local managers traveled frequently between the rural communities they managed and Cajamarca city, 
where they reported to their superiors, attended professional development trainings, accessed administrative infrastructure including computers and the Internet, and spent time with their families. As a result, much of local managers' work was spent in transit, either on the treacherous, winding mountain roads that connected urban and rural spaces, or on the quiet, steep footpaths between villages.

Every month, the local managers drew up a schedule detailing their forthcoming trips and implementation activities. However, they rarely kept to this schedule, as circumstances in the field were unpredictable. Sometimes paperwork sent from Lima was delayed, or whatever Internet access was available in the district capital went out, or they were not able to track down records for new births because the health clinic was closed. ${ }^{2}$ One local manager, Elena, described to me the unpredictability of her monitoring work in the district of Labaconas, which took her between that district and Cajamarca city:

During the first training session, they told us that we could work accumulating hours:
for example, if the month has twenty-two workdays, I could work these straight
through, including Saturdays and Sunday, and the eight remaining days could be
taken as days off, also accumulated, no? I could maybe visit home, do whatever I
like. But when it came to down to it, the work wasn't like that. For example, we're in
the countryside for six days, eight days, then [for some reason] we have to use the
[Juntos online user database] system, so we come to Cajamarca because in Labaco-
nas there isn't Internet; and when there is, it is very slow and hardly works. So I come
back, I'm in Cajamarca for two, three days, and then I go back again, and then come
back again, and that's what it's like... Because all of the information that we gather
in the countryside has to be entered into the system. And this is our work in Juntos.

In order to effectively monitor conditions, local managers were required to be adaptable and resourceful. Implementing Juntos was physically and temporally demanding, and the requirements of the work had gendered costs for the local managers and their families. Local managers were required to spend long stretches of time away from home, which had negative implications for their family life. Of the three female Juntos local managers with whom I interacted closely, one worked while eight months pregnant, another found it difficult to manage childcare, and the third confided that she had no idea how her female colleagues with babies were able to get their work done at all. Given the structure of the work, she imagined that if she were to have children she would have to quit her job. The male local managers who had children, and a spouse at home to assume caring responsibilities, did not have to quit their jobs in order to have a baby, but they did lament the infrequency with which they saw their families. My observations were consistent with a trend identified by other feminist scholars of international development: the historic domination of the public sector by male employees conditioned organizational practices and processes to reflect men's traditional roles and needs, which largely excluded reproductive responsibilities (Goetz 1997). 
To arrive at their respective districts, local managers traveled in combis, privately owned minibuses that were infamous for having intoxicated drivers and for traveling at high speeds over treacherous mountain passes. Within the districts, much of local managers' time was spent visiting villages, many of which are accessible only by foot. During the period of my research, Juntos purchased motorcycles for the local managers to use between villages. They were expected to get training in Cajamarca city on how to operate them. Paulino, one of two male local managers in my fieldwork sites, was very pleased about this; he had already been using the motorcycle provided to him by the district government in Labaconas, and he knew how to operate it. ${ }^{3}$ Female local managers were less enthusiastic. One of the local managers had no intention of using the motorcycle because it frightened her, and another said that she would learn, but that it was scary because it was so large. Local manager Lina described the travel that Juntos required of her:

Unfortunately, there isn't always transportation in the places where I work. Only on Thursdays. But now they've given us a motorbike, just recently this month. Thank God, so now we'll go on the motorbike. But before, I did my work walking. Fifteen hours, twelve hours. Sometimes there is a combi [in which to travel to a central village], so then we have to leave at three or four oclock in the morning to get to the educational institution to verify coresponsibilities. So we manage with whatever we've got, be it combi or motorbike or even on foot to get the job done.

The rumbling combis were not equipped with $\mathrm{Wi}-\mathrm{Fi}$, and so the time spent in transit could not be dedicated to advancing in their work. The hours spent in travel to and from the villages were additional to those considered official working hours; the legally sanctioned eight-hour workday very often became a twelve- or fifteen-hour workday.

In order to capture the data on compliance that policy administrators in Lima required, local managers had to arrive on time at clinics and schools by any means available, even when this required them to rent rooms in family homes in the district capital or sleep in village health posts that were not equipped as overnight accommodations (i.e., did not have proper beds). Renting accommodations in the field placed a significant financial burden on local managers, all of whom also rented or owned homes in the capital city, where their families resided. Local managers often remarked that once the costs of lodging and food were accounted for, they were unable to accumulate any savings. Local manager Lina described the days-long routes she traveled to monitor women's compliance with conditions:

Yes, I stay over[night], I stay up there, Tarita. I stay in the health posts. My route is Cajamarca to Santa Ana, Santa Ana to Seladin, I go through Seladin to Chan Chan, three and a half hours walking. In Chan Chan I verify coresponsibilities in education, and in health. I do that all afternoon and into the night, and then I stay there overnight in the health post. From there I go up walking five hours to Palo Blanco, Nuevo Hallaqui, Matirca, verifying in these communities. So then I start over in 
Palo Blanco and from there go up to San Pablo, again! Another route. I go up from Santa Ana through Bombacana to San Marcos, which is about ten hours. And then from there I come down again, until I arrive at the district capital, and then back to Cajamarca, and start on another route.

The local managers' direct supervisor, Ofelia, described the imperative to collect the data: "The local manager has to verify coresponsibilities. They have to go from sunrise to sunset, in the sun, rain, shade, hail, no hail: it doesn't matter, they still have to go." When experts claim that CCTs are efficient, they typically are not counting the time, expense, and physical effort required of frontline staff to verify conditions in regions that receive disproportionately little investment in basic infrastructure.

When I arrived in Cajamarca, Juntos management had recently implemented a new procedure to monitor and cut down on staff absenteeism. Local managers were required to "clock in" when in Cajamarca city, and to have local authorities such as the school director or mayor sign a paper acknowledging their presence when in the field. The regional Juntos administrator, the local managers' direct supervisor, and three local managers had all told me on separate occasions that instead of traveling in the countryside between communities, some local managers had been turning off their mobile phones and "hiding at home." Some members of management were sympathetic about this alleged practice, acknowledging that local managers' work was extremely difficult. Ofelia explained to me how it looked from her perspective:

There's a percentage of [local managers] who don't get to all of their communitiesfor example, in Cospan. Sometimes as a [supervisor] I'd say, “This guy doesn't work! He doesn't enter the coresponsibilities [information] properly!" So I went to Cospan, and there wasn't a motorbike! I had to walk for seven hours. Do you think with the salary they pay me that I'm going to go there? I'd kill myself! No! So, since then I was able to understand that, as a [supervisor], I couldn't always be so demanding-because we don't see how the [local managers] suffer in the field, the hours they have to walk, how terrible it is.

The demands placed on local managers were obvious to me, too, but I never observed a local manager hiding from work or dishonestly filling out verificationof-coresponsibility forms when she or he had not actually monitored women's compliance. In light of my conversations with local managers and other local Juntos staff, and also my broader observations about the political economy of northern Andean Peru at the time, I'm convinced that local managers had clear motivations for showing up to work and, as they frequently said, "getting the job done."

First, they believed that the mission of their work-helping families overcome poverty-was important, even though they were also critical of how they were required to spend their time. During a conversation in a small, Van Gogh-themed café in Cajamarca city, local manager Elena explained to me that her own social 
position informed how she approached her work: "I was born and grew up in the campo (countryside), in a rural area, so I admire campesinos because I am also campesina, my parents are campesinos. When I return home, my father has his cows, his fields - and I always return there. I like the campo because it is my home, it is my reality. So I feel proud when I see campesino people progress, when they get ahead in life, you know?"

A second source of motivation is that many local managers belong to Peru's new and precarious middle class. ${ }^{4}$ Many new middle-class families are just a little above the poverty line, and a shock such as loss of employment would be devastating. Other than work in the new social programs such as Juntos, employment opportunities were limited in Cajamarca. Even the gold mine, Yanacocha, was laying off employees. Juntos's local managers worked on a three- or six-month contractual basis, and the possibility that the contract might not be renewed was not worth risking. ${ }^{5}$ Local managers were close enough to poverty, whether because it was the subject of their work or because they had been born into it themselves, that showing up to work was the reasonable thing to do. ${ }^{6}$

\section{MASS-PROCESSING COMPLIANCE DATA}

In Lima, experts at MIDIS and Juntos emphasized that the most important work local managers did was, first, to make sure that women and their children used health and education services and, second, to "verify coresponsibilities" (monitor women's compliance), as the local managers referred to it. According to the accounts of local managers, monitoring women's compliance with program conditions at all of the health and education facilities in their districts took approximately a month. The number of schools and clinics they had to visit in each city and village varied. For instance, the health center in the district capital of Santa Ana served hundreds of families, while a small post in an isolated village served far fewer. As noted earlier, in Santa Ana District two local managers shared responsibility for managing 1,710 households. In Labaconas District, two others were responsible for managing 1,004 households. This meant that the two pairs monitored the compliance of 1,710 and 1,004 women, respectively. Yet the most important figures for understanding the scale of the local managers' monitoring work have to do with how many children and pregnant women lived in those households. Local managers were required to track the service usage of every pregnant woman and every child under the age of nineteen residing in a Juntos-affiliated household. If, on average, every mother enrolled in the Juntos program had three children, this would mean that local managers monitored the school attendance and health service usage of 5,130 children in Santa Ana and 3,012 children in Labaconas. The number of pregnant women whose attendance at prenatal appointments they monitored would be in addition to these two figures. By all accounts, local managers were required to mass-process the mothers and children they managed.? 


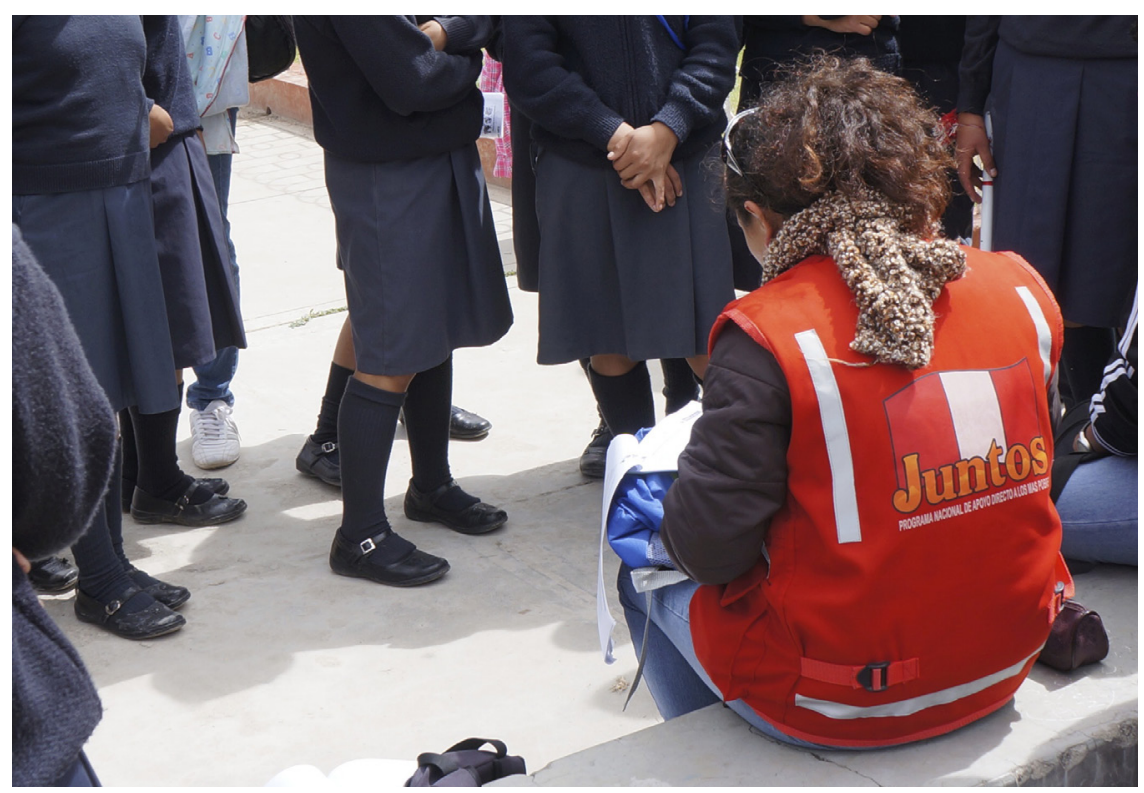

FIGURE 13. Monitoring conditions in education. Photo by the author.

Local managers deployed a number of creative strategies in order to accomplish this mass-processing. When staff at clinics and schools did not cooperate in producing the attendance records and medical records that local managers required, the local managers worked around them. For example at a high school in Santa Ana District, the school administrator was upset that her own children did not qualify for Juntos. As a result, she refused to facilitate the local manager's monitoring work. In response, the local manager deployed what other local managers confirmed was a common strategy-soliciting the attendance information from the students themselves. On one such instance, I observed the local manager ask a small group of students in the school courtyard to summon their peers, and we sat on a bench and waited for them to crowd around us. The local manager pulled the large paper verification-of-coresponsibility forms from her backpack and, taking up a pencil, proceeded to call out the students' names one by one (figure 13). She operated methodically. After calling out a name, she would wait for the students gathered around us to confirm whether that individual was enrolled and attending class. Depending on their response, she would check "yes" or "no" in the corresponding box.

Local managers also used this strategy when they perceived that school administrators failed to keep accurate or updated attendance records. The local managers insisted that children "didn't lie," and that asking them to report on their peers was much quicker than navigating school records. While this method of 
data collection saved local managers time, it was also, from the perspective of Juntos mothers, fraught with opportunities for error. On a number of occasions I watched the local manager record a "no," only to have that student appear running from within the school to correct the erroneous information. Had the student not heard from her peers that she had been marked as no longer attending school, the girl's mother would have been suspended from the Juntos program.

In previous chapters I discussed how frequent clinic closures and absenteeism made it difficult for Juntos mothers to obtain care and meet program conditions in a reasonable manner. The unreliable nature of services also negatively affected the time and effort local managers had to expend on monitoring conditions. On several occasions I accompanied a local manager to a health post only to find it locked up and deserted during "open" hours, with the responsible staff absent. The consequence of this was that the local managers had to return the next day and try again, returning to the clinic until they were able to obtain the data that Juntos required. Even when the health posts were open, local managers encountered complications in collecting the required data.

On a warm day in May, two local managers, Lina and Silvia, and the new local-manager trainee, Felipe, monitored conditions at the central health clinic in the district capital of Santa Ana. Over the course of the previous two days, the local managers had asked mothers from the surrounding villages that were managed by either Lina or Silvia to wait in lines with their children's medical histories so that the local managers could transfer the information into the verificationof-coresponsibility forms. Even after asking mothers to manage up, local manager Lina was still missing compliance data for a number of women and children. As a result, she had to ask the clinic to allow her access to medical files, in which she and the trainee, Felipe, would attempt to locate the missing information. The following field notes describe what this entailed:

We are inside the building, in the obstetrician's office, which has a painted indicator on the wall of the work done there: "Women's Health." The nurse on duty tells Lina that she doesn't have time to help her because she has to attend a delivery, so Lina asks for her book to see the list of births for the past two months. The book is a simple, lined notebook, filled out by hand. Lina and the new local manager start filling out the Juntos forms using the information the notebook provides. Lina also takes information from a chart with pockets and medical histories that is hung on the wall. The medical histories look complicated to me, and the work is slow. Lina tells me that the staff is of no help here, and they never help because they don't know how to fill out the Juntos forms.

Lina and the other local managers can't find a few of the medical histories that they need. After forty-five minutes the nurse comes back and offers to help find the ones they are missing. She reads out the information from them and Lina fills in the form. Nothing is digitized, so it is a process of sifting through histories and personal health pamphlets, although with the nurse's help it is faster. In total, information is gathered for fewer than a dozen women over the course of an hour. Next we go into 
a small room behind the front desk where all of the medical histories are kept, stacks and stacks of folders and pamphlets on metal shelves. Lina has to find the information on the children missed while she was verifying coresponsibilities over the past week. The histories are organized according to village and name, but they look through every folder in a given section because they are out of order. Lina says this is the process in all of the health posts, just looking through files. She spent all Saturday doing this as well. Lina goes to ask the nurse if there are any new pregnant mothers for March or April, and the nurse says yes but they don't have them in one file. The nurse looks for some, gives the names and dates of their last menstrual period, and Lina writes this down. We move on to look for information on the recent births.

Searching through files took two hours at the end of two consecutive long workdays monitoring conditions elsewhere, and Lina (as well as Felipe and Silvia) had to return the following day to finish the task (figure 14). This effort was expended on one clinic and, over the course of a month, was repeated at smaller clinics along the routes that the local managers each traveled.

Filling out the forms used to monitor women's compliance was time-consuming because it required local managers to find and transfer information. The local managers' direct supervisor explained to me that local managers received an email instructing them on how to fill out the education and health forms, and that this level of instruction was inadequate. Whereas the education forms were relatively straightforward, the health forms required local managers to gather and interpret technical medical information (figure 15). The majority of local managers were not trained as health professionals, and as a result, while some local managers reported that they picked up the terms and abbreviations quickly, it took others longer to develop a working knowledge. Medical histories with checkup dates, and vaccination and height and weight data, were often missing information, were illegible, and had bits of paper with supplementary data stapled to them. The local managers navigated these inconsistent paper trails, and they exercised discretion when they were provided with imperfect information. Local manager Paulino, who was a former public school teacher, explained how he and his colleagues relied on whatever help they could get from the health staff:

Paulino: The agreement that the Juntos program has with the Ministry of Health is that the personnel in the health posts will fill out the forms. But they don't do it. We have to do it ourselves. They do help us, because we don't have-we don't know the technical words that the health personnel use. More than anything, we just don't understand, so they help us and support us. ... They use symbols, for example STP, which means a measles vaccine.

TC: Ok, so you've learned a lot.

Paulino: Something, sure. Sure. Or sometimes there is a term about pregnancy that we don't know- "self-measurement," we don't know it; "perimeter" I think they call it-that we don't understand, so we ask and they tell us. 


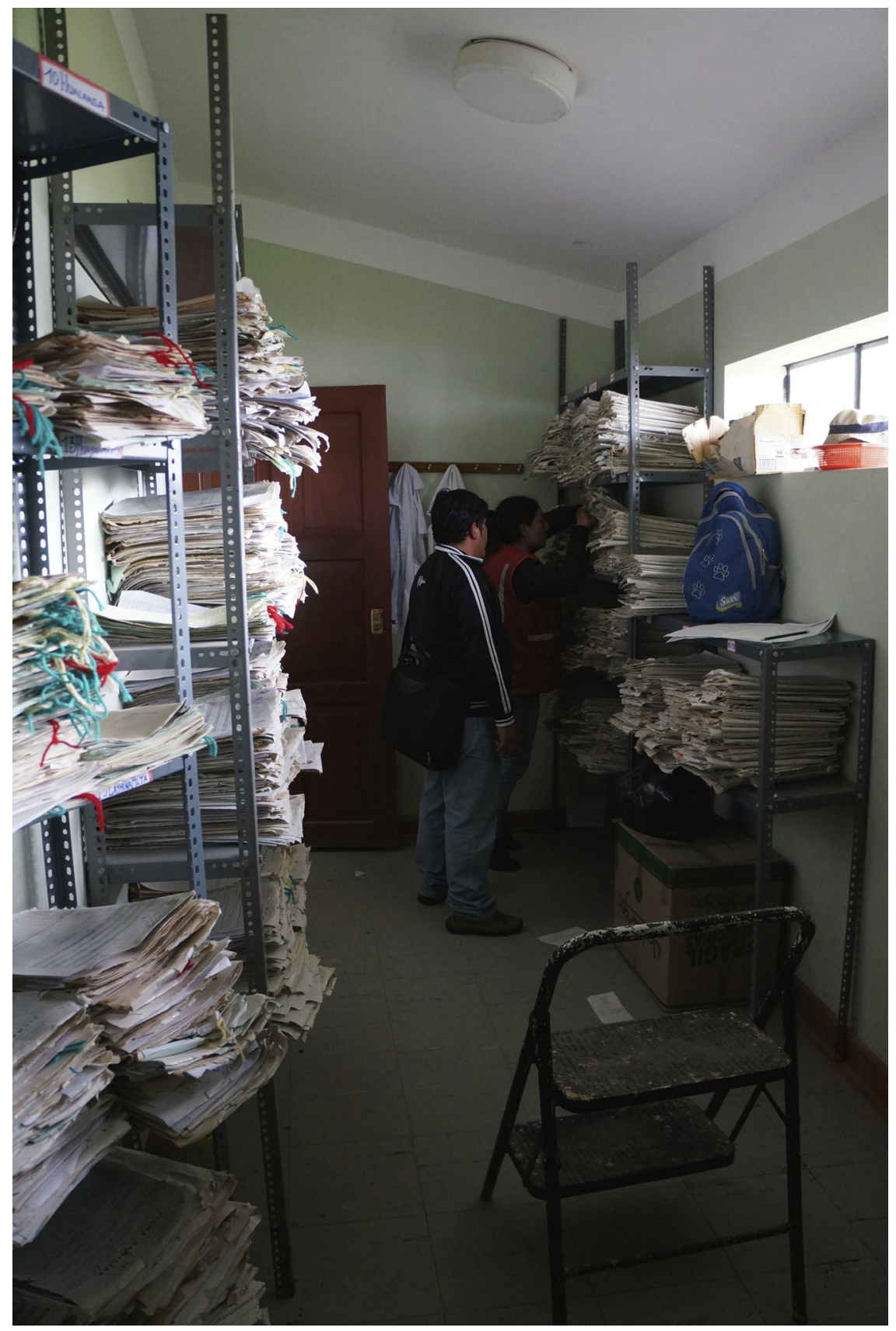

FIGURE 14. Local managers search for missing or misplaced medical histories. Photo by the author. 


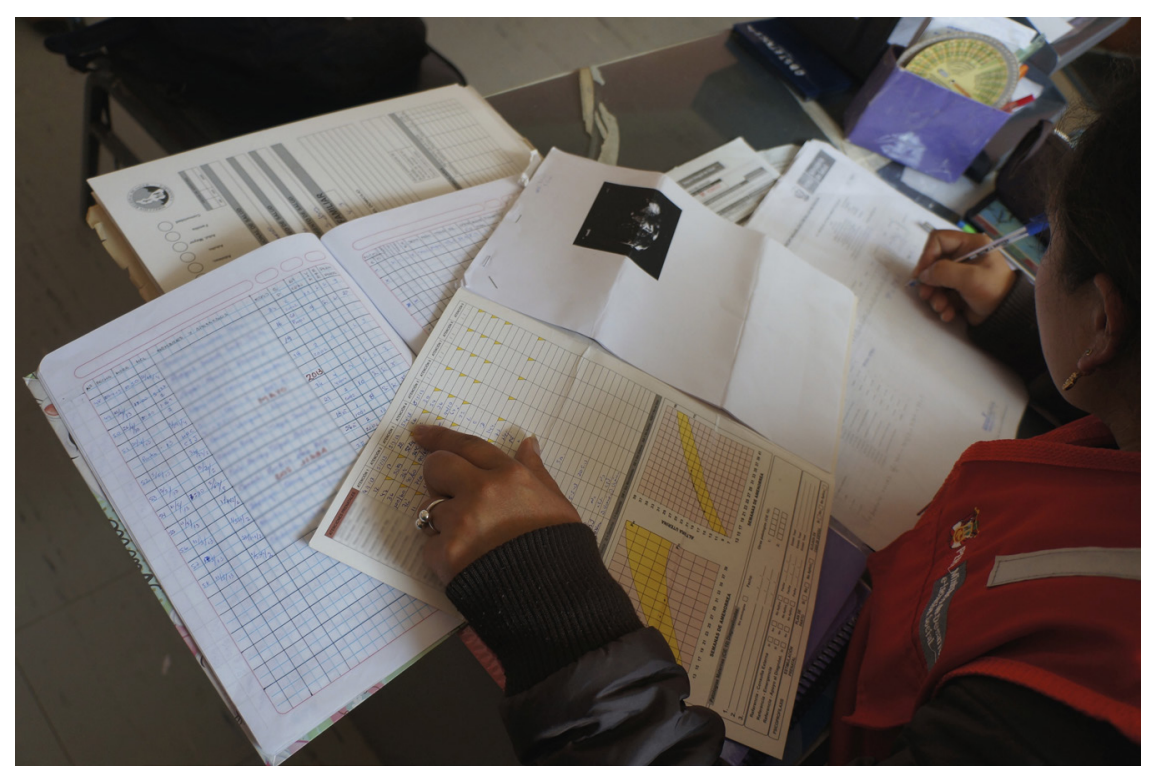

FIGURE 15. Local manager Lina reads a medical history to determine a mother's compliance. Photo by the author.

As local managers and their direct supervisor rightly insisted, it would be misguided to demonize local health staff, who worked under their own institutional constraints and were not trained by their own superiors to fill out the Juntos forms. Their supervisor, Ofelia, describes a conversation with a colleague from university who now works as a nurse. The two of them had been discussing Juntos and the work of monitoring women's compliance with program conditions:

The [health personnel] don't collaborate in the work, no? Despite the fact that it is their responsibility, they don't see it like that-I'd imagine because of their workload. A [university] colleague of mine explained to me that it's terrible to fully complete a [child's growth and development controls], I think she said it takes up to an hour to do it well. "And imagine it now!" she said to us, "when we have all this burden and then on top of it the Juntos program, [whose users] come and demand it of you-and really they demand it of you, because if not they suspend them." . . Imagine that, on top of all this, they have to fill out the coresponsibilities form, that as you've seen is a "bedsheet," as we say [because of the color and size], because it is, you know?

The health and education staff I interviewed did not always agree with the way Juntos was implemented, a finding that corroborates survey data captured by MIDIS (MIDIS 2013a). The head nurse, Lisella, at the health post in Sonsonate had worked in the area for twenty years. She did not approve of the conditional aspect 
of the Juntos program, which she saw as overriding a more important focus on the actual health of the children:

Yes, [the Juntos local manager comes to the clinic]. She comes but ... once a month, or once every two months. The work-well to me it's bad. It's really bad. Because [the local manager] comes and she says, "Eh, let's see, I'm going to [verify coresponsibilities] for the beneficiaries." . . . She comes and takes the [medical] history and she looks over it. "Let's see, this boy," for example, "this boy Andreo, who doesn't have a [national identity document], is five months old, and came on such and such a date and had his checkup." And that's it. That's her work. She doesn't see if the boy is maybe malnourished, and if so, why. Nor does she try to say to [the mother], "Look, you are the beneficiary, they give you this money, they give it to you so that you purchase food for your child." She doesn't see this. She doesn't see this. ... I think that as she is the program representative, she should do this follow-up. None of this telling the family, "Your child is malnourished, malnourished, malnourished," and then what? There isn't a single good result. There aren't results.

Health staff and frontline Juntos personnel, while often frustrated with one another, expressed similar concerns about a programmatic focus on compliance that overlooked more substantive impacts on health and education. While the nurse wasn't aware of the institutional dynamics shaping how local managers used their time, she accurately identified a programmatic prioritization of box checking.

When local managers expended over half of their time sifting through files and filling in forms, they had less contact with the households they managed. This was an (unfortunately missed) opportunity for the state to develop a more substantive understanding of the barriers and constraints women faced in caring for their families. Perhaps even more significantly, it meant local managers had less time for monitoring and reporting on the quality of services that program recipients were required to use. This was also an aspect of the local managers' job description, but one that I never observed being carried out. What the nurse did not articulate was the fact that this dynamic, rather than being a result of local managers' individual decisions, was a result of institutional choices that elided questions about quality and engagement in favor of recording a narrow set of metrics related to behavioral change. As a consequence, the relationship that the state had with rural mothers and their children via the local managers was largely about disciplining behavior and collecting data on how effectively this had been accomplished.

Once the local managers had collected all of the compliance data from the clinics and schools in their districts, they returned to Cajamarca city to input it into "the system," an online database that centralized and processed information for the purposes of determining which mothers would "collect" (cobrar) the cash payment and which would be suspended. Local managers had a tightly limited amount of time to accomplish this work. After the deadline imposed by the head office in Lima, the local managers were unable to emend information. The potential consequence of this for Juntos mothers was erroneous suspension. If 
the local manager did not finish entering all of the data into the system before the deadline, the mothers whose compliance information was left out of the system would be suspended.

In theory, local managers were meant to input the data using the computers at the regional head office. However, because the Cajamarca office was cramped and there were not enough computers to go around, several of the local managers brought their verification-of-coresponsibility forms to one of two Internet cafes and entered the information there. This was often done at their own expense, as local manager Elena explained to me: "Yes, we pay [for the Internet ourselves]. At first they gave us ten hours of [reimbursed] Internet [access], but these days I think that the budget-well, as there is no administrator, ${ }^{9}$ eh, they haven't given it to us. We have to pay for it out of our own pocket. . . But like I said, these days there's nothing. So if you don't finish your work in these ten hours, you have to pay out of your own pocket [in a café] wherever you want."

I observed Elena input data over a period of three days. In the crowded and noisy Internet café, she positioned the stack of completed forms below the keyboard on her lap and worked carefully to transfer the information correctly, double-checking her work before pressing "submit." It seemed to me that in spite of her diligence, there was a significant margin for error in this process owing to the distractions of the busy public café and the sheer size and detail of the forms. When deadlines were tight, local managers who had Internet access in their houses resorted to taking the forms home and soliciting family help. The local managers' direct supervisor, Ofelia, explained to me that the time-pressed task of entering data into the system also involved resources in addition to Internet access:

I've always said this, and I also have evidence of it, that working for Juntos, Tara, is a family job. Because if you go to a local manager's house, in the field they collect a mountain of paperwork-birth certificate photocopies and things-because they have to update their work in the office too. So what happens? [She] is in her house with her boxes of paperwork, and her son knows how to do the titleholder change, and if her children are already in primary or secondary, they're entering the system! And her husband is filing [paperwork] in the folders, and the grandparents. I'm convinced that if you ask any family member of a Juntos worker, they know what a "titleholder change" is, they know what a "coresponsibility" is. They know because that's how a Juntos worker is, that's how their work is. ${ }^{10}$

This practice, which was not officially sanctioned by Juntos superiors, highlights the effort and cost of monitoring women's behavior and producing the data meant to demonstrate that imposing conditions is effective.

In addition to inputting compliance information every two months, local managers were responsible for keeping the system updated with other relevant information about the Juntos mothers' eligibility. For instance, when a baby was born to a Juntos mother, local managers were tasked with affiliating the baby to 
the program. Conversely, if a local manager discovered that a household was not meeting program conditions-for instance, if a youth had dropped out of school, or if a Juntos mother had migrated for work and was not residing in Juntos's area of intervention, the local manager was required to suspend the household through the online system. In order to do so, the local manager needed a functioning Internet connection. However in rural areas, Internet connectivity was limited to the district capitals, and even there it frequently failed. As a result, local managers often made unscheduled and time-consuming trips back to Cajamarca city when they needed to verify or update information regarding a Juntos user.

This was made very clear to me one day when I was observing the work of local manager Paulino in Labaconas District.

During his rounds of the village, Paulino receives a call from Paula, the Juntos regional director. She asks him to come back to Cajamarca because there are twentyfive kids that have been missed in the system and, if they are not entered, then the mothers will not get their money on the upcoming payday. So we go to the municipal hall to try to "enter the system," but the Internet in the mayor's office is not working. The other local manager with whom he shares this district, Elena, is in Cajamarca but is not answering her phone, so Paulino says he will have to return to the city to do it. He tells me this is inconvenient, because it is expensive for him to return and come back to Labaconas again the next day. He decides to break for lunch and try again afterward.

Later on, we return to the municipality to try the Internet in the office of the Glass of Milk Program director, who has offered Paulino the use of his computer. The Internet is very slow, but it works after the director resets the modem a few times. Paulino's new Juntos email account does not work, but he manages to get hold of Elena and she gives him the password to hers. In the email it turns out that there are seven children missing from the registry, not twenty-five. Paulino enters the children into the system. The Internet crashes several times, and he must start from the beginning each time. Because of the Internet problems, the whole process takes just under two hours. From what I can see, with a functioning Internet connection it should have taken fifteen minutes at most.

Because of the hours spent trying to access the Internet, Paulino was unable to attend to other tasks, including visiting a health post. On this particular day, he had no contact with Juntos mothers or their children, or local health or education staff. The only reason he did not have to make the long trip back to Cajamarca city to ensure that women's compliance was properly registered was because of the relationships he had formed with the municipal government, a member of which allowed him use of his imperfect Internet connection. Many of the Juntos staff that I spoke with who worked in the Cajamarca region told me that they believed Juntos's mission, to help people overcome poverty, was a good one. Yet situations like these were frustrating. Local managers felt that they spent too much time on activities that did not make a difference. 
Despite the difficulties local managers encountered in meeting their professional responsibilities, I observed that, by and large, they "got the job done." Imperative to doing so was the support of local actors who were not on Juntos's payroll. Local managers built relationships with health, education, and other social service personnel in the communities where Juntos intervened. These relationships provided them with the resources that Juntos did not always provide: transportation, Internet access, a place to sleep. Local managers also relied on an additional group of local-level actors who were not on the payroll of any government body at all-Mother Leaders. The next section explores local managers' relationships with other professionals and their relationships with Mother Leaders.

\section{MOTHER LEADERS}

One of the local managers' more significant resources for getting their work done was a select group of Juntos recipients called Mother Leaders. ${ }^{11}$ In the opening paragraphs of this chapter I described an election for a new Mother Leader committee in Tinca village in Labaconas. That particular committee consisted of six members, although my research revealed variation in the formation and presence of Mother Leader committees elsewhere. Some villages had a single Mother Leader, while other, larger villages had a hierarchically organized committee of six or eight members including a president, treasurer, secretary, and so on. Mother Leader committees in the districts of this study ranged between two and eight members. In 2010, there were a reported 687 Mother Leaders throughout Juntos's area of intervention (Vargas Valente 2010), although a rough calculation based on Juntos-hosted workshops with Mother Leaders in the same year suggests that there might have been nearly twice that many. For perspective, this means that Mother Leaders far outnumbered local managers.

Local managers in Labaconas and Santa Ana worked in close collaboration with Mother Leaders, and for this reason, they developed preferences regarding the characteristics of the ideal Mother Leader. Most of the Mother Leaders in the fieldwork sites of this study were literate. Before arriving at the meeting in Tinca, the local manager recounted that he and his colleague had decided that they would accept only literate candidates who had at least a minimum of primary school education, remarking, "If not, how are they going to serve their community?" According to another local manager, "The Mother Leader has to be someone who at the very least knows how to read. And who is dynamic, attentive. No? Who likes to participate, is someone who works on behalf of her companions." Some Mother Leaders had previous experience as promotoras comunales (voluntary community workers) in other social programs, and they tended to be the most outspoken Juntos recipients at community meetings. All of the Mother Leaders I interacted with owned mobile telephones, which they used to communicate with local managers, although they often (understandably) complained that Juntos did not compensate them for the cost of airtime. 
Local managers often explained to me that the Mother Leader was "the local manager in her community." This description pointed to the important role that these women played in program implementation. One of the few mentions of Mother Leaders that I could locate on the Juntos website was a press release that described the role of Mother Leaders as follows:

In every community where Juntos intervenes, Mother Leaders help local managers guide and sensitize Juntos mothers so that they meet their coresponsibilities regarding health and education. Regarding health conditions, the Mother Leader helps identify pregnant women and promote the registration of all members of Juntos households for Public Health Insurance (SIS), attend health checkups, and through the local manager, inform Juntos if the household members are treated well in health establishments. Regarding education, the Mother Leader helps to identify all schoolage minors in Juntos households, ensures that they are enrolled in and regularly attend an educational institution, and contributes to preventing tardiness, absences, and dropouts (UCI 2013).

My village-level observations confirmed that Mother Leaders performed many of these tasks, in addition to meeting the conditions that were imposed on Juntos recipients. Through these tasks, Mother Leaders helped local managers implement Juntos, and they also helped other mothers ensure that they received the cash incentive.

The press release above suggests that Mother Leaders would help Juntos understand how mothers were being treated in health establishments; my research shows that this point is highly questionable. As discussed in chapter 2, experts at Juntos and MIDIS were well aware of the poor quality of health services in rural Peru. Given what the experts perceived to be their inability to improve the services, they had narrowed the program focus to making sure that women and children used the services available, quality notwithstanding. Bearing this in mind, I'd like to further explore the contributions of Mother Leaders in the context of a narrow programmatic focus on achieving women's behavioral change. Put otherwise, how were Mother Leaders implicated in enforcing conditionality?

\section{BEING THE STATE'S EYES AND EARS}

Local managers relied on Mother Leaders to help them maintain a presence in Juntos communities when they could not be there themselves. When I interviewed head office staff from the Verification of Coresponsibilities Unit in Lima, which was charged with overseeing policy and practice related to conditionality, they described Mother Leaders as the local managers' primary point of contact in the field: "When the local manager returns [to the district], their first point of contact to learn about what has happened in these fifteen or twenty days in which the local manager hasn't been there, is the Mother Leader." This dynamic of Mother Leaders' work was given an embodied quality in a Juntos training guide: 
REMeMber! the Mother Leader is the eyes and ears of the Juntos Program in their community. We value the support they offer the Juntos Local Manager, by informing them of the needs of beneficiary mothers and of any change in the socioeconomic situation, family composition, residency status, health problems, access or difficulties fulfilling coresponsibilities, new pregnancies, recent births, and changes to school enrollment that might come up in the households of their communities (Juntos 2011, original emphasis). ${ }^{12}$

Local managers relied upon the information that Mother Leaders provided them to ensure that the Juntos database was up to date, and that only those women who met the program requirements received the cash payment. In practice, acting as the Juntos program's eyes and ears meant monitoring the behaviors of their neighbors.

This eyes-and-ears dynamic was evident at a meeting in the district capital of Labaconas, when the Juntos regional coordinator asked a roomful of quietly seated Mother Leaders to inform their local managers about households that had "unregistered" children. ${ }^{13}$ One of the local managers then read aloud the names of children whose identity document numbers were missing from the system, so that Mother Leaders could collect the required information. On this and other occasions, local managers relied on Mother Leaders to help them accomplish administrative tasks, as Paulino explained to me: "Another job [Mother Leaders] have is to collect documentation[,] . . . copies of national identity documents, copies of birth certificates, copies of proof of enrollment." The local managers' preference for literate Mother Leaders was understandable given that they were required to keep detailed records. According to local manager Elena, “The Mother Leader will have her notebook where she writes down the name of the program user, her children, their respective grades, the histories of each child; and if, for example, the mother is pregnant they write 'expectant mother', and if the child has been born they go ahead and fill in the notebook." These administrative tasks helped mothers maintain updated records with the program, therefore avoiding suspension on account of missing or erroneous data. Their support also enabled local managers to get their work done.

Not all of the monitoring and informing work done by Mother Leaders had favorable consequences for other Juntos mothers. In addition to gathering data that proved women had met program conditions, Mother Leaders were asked to provide local managers with information that potentially had negative consequences for women, including suspension. Local manager Paulino explained this to me in an interview: "For example, [Mother Leaders] inform us that such and such child doesn't live in the community anymore, and so we process [the relevant] documents to disaffiliate these children. ... They also tell us when mothers aren't living in the communities anymore-maybe for work they went to Lima, they went to Cajamarca city, so then we go ahead and disaffiliate these mothers." There were no institutional controls in place to ensure that local managers verified the authenticity of the third-party information they received. As a result, wrongful 
disaffiliations were always a possibility. If communities were always harmonious, this would not present an issue. However, tensions existed between some Mother Leaders and the Juntos recipients in their communities. Because Mother Leaders' committees were unregulated components of the program, there were no clear accountability mechanisms in place.

For Mother Leaders, being Juntos's eyes and ears sometimes entailed reporting on personal circumstances and choices that fell outside of the program's remit (which was to improve access to high-quality public health and education services). On several occasions I observed Mother Leaders-as well as a number of non-Juntos community members-inform local managers about CCT recipients whom they thought were spending the transfer on clothing or inappropriate food choices. As a matter of policy, Juntos did not officially direct women on how they should or should not spend the cash incentive. However, local managers had personal beliefs, and the way Juntos was organized gave rise to local managers' interest in certain issues, including consumption. One local manager explained in an interview how she had very few "problems" with mothers in her district insofar as their spending practices. Nevertheless, the Mother Leaders helped her to maintain an awareness of dynamics that could become "unsatisfactory": "[The program recipients] know that the Mother Leader is checking on them. We have a Mother Leader in every community, so, for example, they tell us: 'Miss, she is misspending the money, no? So then, right away we go straight to this person. ... [T] he Mother Leaders are who checks in; they support us, they know."

Understandably, a great deal of this was information that CCT recipients did not want to share. For instance, local managers frequently implored Mother Leaders to inform them when women in their communities became pregnant. Yet according to Lourdes, one of the Mother Leaders: "[The women] don't want to tell us." While attending prenatal exams was a requirement for pregnant women in order to receive the cash transfer, some women resisted releasing intimate information-such as the date of their last menstrual period-to Juntos staff. When Mother Leader Soledad urged a Juntos recipient to report her pregnancy to the local manager, the woman replied, "And Juntos, who are they? My husband?" The response of local managers to such resistance was to tell Mother Leaders that the women had to report their pregnancies whether they liked it or not; otherwise, "they'll be suspended."

Feminist scholars have suggested that the CCT program design positions poor mothers as "conduits" for a policy that seeks to improve the health and education of their children rather than the women themselves (Molyneux 2007). A focus on Mother Leaders showed this dynamic to be even more pernicious: as Mother Leaders were asked to participate in modifying other women's behavior, they were positioned as conduits for official policy and potentially whatever else local managers sought to improve or achieve. ${ }^{14}$ Local managers frequently asked Mother Leaders to "guide" Juntos recipients in ways that diverged from official policy 
directives. In the meeting described at the opening of this chapter, the local manager encouraged women to make use of the municipal government's guinea pig initiative and to attend the reproductive-health training with their husbands, so as to interrupt the pattern in which women "continue having more and more babies." While Juntos did concern itself with children's nutrition insofar as it incentivized and tracked attendance at health checkups, local managers were not required to foster microentrepreneurship or monitor household consumption. Juntos incentivized pregnant women to attend prenatal checkups, and the local manager's job was to audit their attendance. Curbing (speculative) fertility rates was not part of the Juntos program's remit at all, and the number of children a woman reared was not the business of the local manager.

To be sure, educating parents on children's nutritional requirements or raising awareness about available reproductive services is not inherently wrong. My point is that Juntos created a situation in which poor women's personal choices became monitored and disciplined by their own neighbors. At the request of their local managers, Mother Leaders became entangled in the disciplining and surveillance of women's behavior that bled beyond what we might think of as "official" policy concerns.

It would be deeply misguided to locate the root of this unfavorable situation with the Mother Leaders. The World Bank suggests that Mother Leaders "can be useful in helping [CCT] clients understand the rules and verifying that complete and correct information is being used" (Grosh et al. 2008). The rules, however, were not transparent at the village level. They were no more transparent to the ordinary Juntos mothers than they were to the Mother Leaders. With local managers as their primary points of contact-or direct supervisors, really-Mother Leaders had very little access to alternative information. Whether the activities requested of a Mother Leader were officially sanctioned was not readily available information. Rather than viewing this practice as an aberration in an otherwise well-designed program, it is better understood as a reasonable outcome of imposing conditions and insisting on their measurement in a context of inadequate infrastructure and highly unequal power relations.

\section{DEVELOPMENT THROUGH DISCIPLINE}

Mother Leaders' work was guided by the same notion of "responsible motherhood" that disciplines women's compliance with program conditions in Juntos (and other CCT programs) more broadly (see Molyneux 2006). One morning I interviewed Mother Leader Eufemia in a new addition to the house she shared with her husband and children. They had received a grant from the national Techo Propio (My Own House) program for the construction. The room, which wasn't yet furnished, was a source of great pride to Eufemia-the house was now one of the nicer homes in the village. We sat on a shawl that Eufemia spread 
out on the cool concrete floor, and she spoke to me about what it took to be a Mother Leader:

TC: What qualities do you look for in a Mother Leader? Why might you select one person over another?

Eufemia: Well, above all she has to be responsible. Responsible.

TC: Sure. And what does that mean?

Eufemia: Well, for those who don't meet the conditions, the Mother Leader writes it down on a paper and gives it to the local manager. They do informing.

TC: The Mother Leaders do informing?

Eufemia: Yes, they inform the local manager. So then the local manager suspends those who don't meet their conditions.

At one community meeting, local manager Paulino told Mother Leaders that their role came with responsibilities: "As leaders, social agents in your communities, you have responsibility, authority." Unfortunately, much of the work Mother Leaders were asked to do related to disciplining the individual behaviors of poor women so that they met the requirements of the state. In this context, a job well done involved promoting the state's definition of responsible motherhood (i.e., meeting program conditions), monitoring others to make sure program goals were met, and helping local managers navigate both an expansive territory and the impossibility of knowing the intimate details of all of the households they were responsible for managing.

The state's reliance on these women leaders to discipline their neighbors and make them more responsible mothers has social costs that are worth considering. A 2009 study conducted by the think tank Instituto de Estudios Peruanos suggested that Mother Leaders presented an opportunity for Juntos to develop a closer relationship with its target population. In theory, the democratic election of a group of women intended to advocate on behalf of the oft-marginalized women of their community-in a spirit of solidarity and empowerment-seems like a hopeful and important advance for community-led development. Such an arrangement could lead to an increase in power not only for the elected women but also for the community as a whole. Imagine, for instance, the state equipping Mother Leaders with tools that would enable them to report on poor service quality and hold the state accountable. ${ }^{15}$ The think tank's study, however, found that the opportunity was unrealized. Researchers discovered that Mother Leaders' committees frequently functioned as a mechanism for control of beneficiaries that "runs the risk of becoming oppressive" (IEP 2009). Among the concerns raised was the tendency for these committees to reproduce the hierarchical and authoritarian relationship between local managers and CCT recipients, which "emphasizes discipline over promotion of rights" (IEP 2009, 38). 
I also observed the authority that Mother Leaders were granted run awry. Much like local managers, Mother Leaders could compel Juntos recipients to do things under threat of suspension that extended beyond what Juntos actually required. During informal conversations in one village, Juntos recipients told me that their Mother Leaders had called a meeting to request that they contribute part of their cash incentive toward a fellow Juntos recipient's medical costs; the woman's son had broken his leg. Upon further inquiry, Custodia, one of the Mother Leaders involved, said that she thought this was a reasonable request. In subsequent interviews, Juntos recipients reported that collaboration was obligatory. For instance, Juntos recipient Pepita said to me: "[The Mother Leaders] called a meeting and told us we have to contribute five soles, and if we don't contribute then they'll complain to the program that we didn't want to." I verified these Juntos mothers' reports in an informal discussion with the local manager later on. The local manager confirmed that she had given her support because she believed that it was the right thing for the mothers to do. Most Juntos mothers' accounts of the situation suggested they were unhappy about having to contribute, especially given news that the woman's son had been drunk. Despite this, the women had complied with what the Mother Leaders had asked and the local manager had sanctioned.

Rather than faulting individual Mother Leaders, it is worth considering how authority, the coercive power of an incentive, and a stretchy definition of responsible motherhood shaped this situation. Local managers called upon Mother Leaders to help them implement a set of ambiguous program conditions, and they did this by appealing to their sense of responsible motherhood. Mothers had already critiqued the irony of having to take children to short-staffed schools and unstocked clinics in order to be defined as "responsible mothers," and so being told to contribute to a broken-leg fund likely came as no surprise. What this scenario also illustrated was the distressing misuse of Mother Leaders' labor. Although development experts suggested that Mother Leaders could be empowering resources for CCT recipientsby, for instance, reporting on the quality of services - the potential for such an outcome is undercut by the very assumptions upon which CCTs are designed. CCTs are intended to change the behavior of individual mothers, not improve the rough conditions and paltry services with which they must contend. As a result, the tasks Mother Leaders were asked to perform had more to do with discipline than with group solidarity or empowerment. Instead of asking Mother Leaders to help state staff develop a deeper understanding of the barriers that rural women and their families faced, the state asked them to enforce a set of ironic conditions.

\section{UNPAID LABOR AND MOTHER LEADERS}

Mother Leaders did not appear on any organizational diagram, and they were not on Juntos's payroll. Yet by their own admission, local managers could not successfully implement Juntos without Mother Leaders' help, so it makes sense that staff would 
insist that Mother Leaders were "the local managers in their communities." Mother Leaders were, by all accounts, an institutionalized component of the program.

As much as the local managers confronted inadequate public transportation, so too did Mother Leaders, although they did not have access to institutional resources, like the municipal motorbike. Mother Leaders often commented to me that they spent a great deal of time walking in order to fulfill the tasks corresponding to their role. Acting as Juntos's eyes and ears required time and effort. At the meeting described at the opening of this chapter, the local manager acknowledged that Mother Leaders' work was "self-sacrificing," to which the mothers chorused in agreement. The substantial time commitment and lack of compensation that I observed in Cajamarca corroborated research with Mother Leaders elsewhere in Peru that noted an increase in women's time poverty (Vargas Valente 2010). Mother Leaders assisted local managers to ensure that women met their conditions and received the cash transfer. They helped Juntos achieve high rates of compliance and, as a result, fostered the circumstances in which Juntos was able to claim success in achieving an uptake of health and education service usage.

Despite their significant role in implementation, Mother Leaders were given very little recognition in official policy spaces. They were not featured in organizational diagrams and directories, even though they outnumbered local managers, and they had a marginal presence in external program reports and evaluations. The discrepancy between what I observed on the ground and how Mother Leaders featured in official accounts of implementation was deeply puzzling. When I asked for clarification from high-level experts at MIDIS and Juntos in Lima, they insisted that the relationship between Juntos and the Mother Leaders was informal:

TC: Are the Mother Leader committees a formal part of the program or not? Expert: No. The Mother Leader is a figure that exists at the margin of Juntos. ... [Mother Leaders'] activities are not a part of the Juntos program. We consider her a, a strategic ally of the community when we want to spread information, when we want to promote some activity, or if we want to listen-How is the service going? ... But they are not part of the structure of Juntos.

TC: So there is no promotion of their activities?

Expert: Of the Mother Leaders, no. Nor are they paid. Absolutely nothing. It's a chore.

Experts claimed that while Mother Leaders were useful to Juntos from time to time, they were in effect outsiders to the program. This claim stood in stark contradiction to what I observed when shadowing local managers, who also emphasized the critical role that Mother Leaders played in program implementation. From this view, Mother Leaders were not "marginal" at all. 
We might attribute the disconnect between how experts in Lima and local managers in Cajamarca talked about the role of Mother Leaders to a gap in experiential knowledge. Could it be that experts were unaware of the extent to which Juntos relied on the participation of Mother Leaders? To be sure, Juntos was administrated and implemented by two distinct sets of actors in geographically disparate areas. As a result, policy administrators in urban Lima were not regularly exposed to the everyday undertakings of implementation work. That said, in addition to the occasional policy document, there were other indications that experts in Lima were very much aware of the role Mother Leaders played in implementation. MIDIS and Juntos sponsored a number of workshops for Mother Leaders and released communications on the Juntos website detailing actions Mother Leaders had taken in conjunction with local managers. Staff at the Verification of Coresponsibilities Unit at Juntos headquarters in Lima shared with me their experiences organizing workshops with Mother Leaders in the southern Andean regions. All of the evidence suggested that Mother Leaders were not unknown to those in Lima.

Another explanation for why experts in Lima downplayed the role of Mother Leaders relates to gendered norms about women's "voluntary" labor. A common assumption all over the world is that the largely care-based activities that women perform in households and communities are not work and, therefore, that they are not entitled to compensation. Mother Leaders were referred to as volunteers by experts in Lima and in the few policy documents available, including one published by the World Bank (Grosh et al. 2008). Considering this possibility, what are the implications of the country's largest social program relying on an unpaid workforce of more than a thousand poor women?

Peru has a long history of relying on the unpaid labor of volunteers-mostly women - to fill holes in the social safety net and provide a variety of services where the state failed to do so. In response to this point, experts at MIDIS and Juntos suggested that Mother Leaders emerged from preexisting community networks such as water committees and savings committees that operate throughout the country. Some of these committees, like the community justice committees called rondas, were traditionally made up of men (Gitlitz and Rojas 1985). Many other committees took up traditionally maternal concerns and were composed only of women.

For instance, low-income rural and urban mothers in Peru have historically organized into committees that addressed their "practical and strategic interests" (Molyneux 1985). These committees were particularly important during the 1980s and 1990s, when the World Bank and International Monetary Fund imposed structural adjustment policies on Latin American countries. As state governments peeled back the few social supports that were in place, they simultaneously devolved responsibility for care of children, the sick, and the elderly to women in households and communities (Benería and Sen 1981; Feijoo and Jelin 1987; Rocha et al. 1989). In response, women formed neighborhood-based organizations, 
including communal kitchens, Mothers Clubs, and the Glass of Milk Program (Boesten 2010; Oliart 2003; Barrig 1991). These committees demonstrated "women's ability to establish informal networks of solidarity to help each other in their daily lives and with their family obligations" (Vargas 1991, 21). They helped women advance their practical interests as mothers and, at the same time, provided an opportunity for some women to advance their strategic interests through access to public spaces and power, at least at the local level.

Did Mother Leaders committees present an opportunity for women to build solidarity and help one another meet practical and strategic needs? My observations suggested this was unlikely. To be sure, Mother Leaders helped the women in their communities understand what Juntos required of them and, conversely, ensured that local managers had the information necessary to register a mother as eligible for Juntos. In these cases, women's practical needs were met because they received the cash payment. It is also true that Mother Leaders might have made individual gains. The women to whom the Mother Leader role was available were offered an opportunity to exercise individual rights and maintain an increased presence in the public sphere, at least at the community level (IEP 2009). ${ }^{16}$

These kinds of opportunities do contribute to increased self-confidence and self-esteem (Vargas Valente 2010). These benefits might explain why Mother Leaders were willing to do the work required, including monitoring and informing on their peers, in spite of the time-intensive and physical work. ${ }^{17}$ Yet the thrust of Mother Leaders' work was not to empower poor women collectively, or even to support them in their caring tasks. Being Juntos's eyes and ears was intended to help the state enforce a set of conditions meant to benefit children; the specific sense in which the state benefited from this arrangement bears further interrogation.

When women and their labor have filled gaps in the social safety net, it typically isn't only children, the sick, and the elderly who benefit. Women's unpaid caring labor also subsidizes the state. Let's look at a historical example from Peru. One of Peru's largest social programs before Juntos was Glass of Milk, which tackled malnutrition in children and pregnant and breastfeeding women. The program was born out of a protest march in Lima in 1984, when an estimated twenty-five thousand mothers took to the streets to demand that all children had the right to one glass of milk a day (Copestake 2008). Glass of Milk, which is still active today, draws on federal-level funding that is allocated to municipalities to provide local women's committees with milk, cereals, and other foodstuffs. The committees then disburse these goods to mothers from registered low-income households. Like the Juntos Mother Leaders, Glass of Milk committees are composed of elected members who serve in specific roles, including director, treasurer, secretary, and so on. Without these unpaid committee members and the labor of thousands of other volunteers, the Glass of Milk program could not function. In fact, an evaluation conducted by the United Nations Development Fund for Women found that in 
one community, women's voluntary labor subsidized 23 percent of the $\$ 3$ million budget (Razavi 2007a).

Comparison with the Glass of Milk program provokes an important set of reflections. If Juntos were unable to rely on a cadre of available, mobile women from local communities, the agency would be forced to contract a significant number of additional local managers, all of whom would expect a paycheck. Juntos's reliance on women's unpaid labor has at least two important implications. First, it undercuts the claim that CCT programs are efficient. Put more bluntly, perhaps conditional cash transfer programs are "cheap" only if a large portion of the labor used to monitor compliance is unpaid.

Second, it throws into sharp relief the absurdity of a social program that reinforces gendered drivers of poverty or, put more sharply, the absurdity of promoting children's well-being at the expense of their mothers. Women's poverty is a persistent feature of the social fabric in Peru and elsewhere, and it is persistent in large part because the majority of the caring work that women undertake in households and communities-whether disbursing fortified milk, nursing babies, or caring for the infirm-is not recognized as work worth compensating financially. Even if Mother Leaders committees offered women opportunities for collective empowerment, solidarity, or character growth, the state's failure to compensate these women for their labors functions as a ceiling to how much they are able to improve the living conditions of their families. Roughly half of the children in Juntos households will grow up to be women; these women are unlikely to look back and see Juntos as having had a sustained impact on their lives if society continues to insist that so much of their labor isn't worth compensating.

\section{CONCLUSION}

Mother Leaders' work exists in the shadows of the state; their labors aren't an "official" part of the policy, but they are necessary for it. The fact that Mother Leaders' work is substantial and unpaid undercuts the claim that conditionality has been implemented efficiently. Juntos was unviable without the availability of unpaid, literate, able-bodied, locally based laborers. Without them, the state would have been forced to invest much more money than it already did in human resources. The state relied on Mother Leaders to achieve high rates of compliance and avoid infiltration of the program by "undeserving" mothers. It just did not value Mother Leaders enough to pay them.

In a sense, Mother Leaders do exist at the margins of the program. The fact that they do essential implementation work and are not compensated for it illustrates how CCTs reproduce gendered drivers of poverty. While some individual gains might be had by some of the women, poor women on the whole lose out. To be sure, that women throughout Juntos do a great deal of extra-and inefficientwork at the behest of the state might be justified if we could count on the state 
to use its power over these women to achieve just ends, including for the women themselves. Juntos is by all accounts a well-intentioned social program, and the actors who design, administer, and implement it also have good intentions. But does state power flow through Juntos in ways that are consistently just? The next chapter tackles this question directly, examining what else happens in the shadows of conditional social policy. 